\title{
Research on Subgrade Differential Settlement Control Standard and Treatment Technology Based on Driving Comfort
}

\author{
Xuancang Wang $\left(\mathbb{D},{ }^{1}\right.$ Longting Ding $\mathbb{D}^{1},{ }^{1}$ Wenze Gao $\left(\mathbb{D},{ }^{1}\right.$ Mengyuan Zhang $\mathbb{D}^{1}{ }^{1}$ \\ and Linjie Fu (iD ${ }^{2}$ \\ ${ }^{1}$ School of Highway, Chang' an University, Xi' an 710064, China \\ ${ }^{2}$ Tianjin Municipal Engineering Design and Research Institute, Tianjin 300392, China
}

Correspondence should be addressed to Longting Ding; dltphd2018@163.com

Received 3 September 2019; Revised 15 January 2020; Accepted 31 January 2020; Published 5 March 2020

Academic Editor: Erdin Ibraim

Copyright (C) 2020 Xuancang Wang et al. This is an open access article distributed under the Creative Commons Attribution License, which permits unrestricted use, distribution, and reproduction in any medium, provided the original work is properly cited.

At present, the geogrid is commonly used to treat the differential settlement of the subgrade at the joint of the filling and excavation effectively. In order to further improve the utilization rate of geogrid in the treatment of subgrade, the driving comfort index was proposed innovatively to control the subgrade differential settlement. Based on the human-vehicle-road coupling system model, the influence of subgrade differential settlement area, subsidence value, and vehicle speed on the maximum vertical acceleration of the human body was analyzed. The correlation between the vertical acceleration of the human body under different vehicle speeds and the differential settlement value was obtained through multiple regression calculations, and the subgrade differential settlement control standard based on driving comfort was proposed. By establishing the finite element model of the cut to fill subgrade, the characteristics of differential settlement at the top surface of the subgrade under different geogrid laying positions, densities, and lengths were calculated and analyzed. In addition, the differential settlement layout scheme of the geogrid disposal subgrade based on driving comfort was proposed, and the effectiveness of the scheme was verified by experiments. The results show that the position and length of the grid are the main factors affecting the treatment effect of the vertical and horizontal cut to fill subgrade. The proposed layout scheme can effectively control the differential settlement of the subgrade and raise the utilization rate of the geogrid. The research results can provide theoretical value and reference for the laying of geogrid in mountainous roads.

\section{Introduction}

Filling and digging joints are inevitable during the process of building a new highway, which poses new challenges to the subgrade stability. If the subgrade is improperly treated, it will easily cause the early longitudinal and transverse cracking of the pavement structure, leading to the uneven subgrade settlement and reducing the comfort of the passengers inside the car. In the existing projects, the geogrid treatment can treat subgrade differential settlement effectively. However, since the geogrid is buried in the subgrade soil, it is difficult to obtain the working state of the geogrid. The design and construction schemes are mostly based on engineering experience, resulting in the low effective utilization of geogrid technology in subgrade treatment $[1,2]$.
As a kind of reinforced material, geogrid can restrain the lateral deformation of the soil and increase the shear strength of the soil, so as to ensure the overall stability of the superstructure [3-5]. Many scholars have investigated the application of geogrid to the cut to fill section and widening subgrade. Hu et al. analyzed the mechanism of geogrid-reinforced subgrade soil through the indoor triaxial test. Furthermore, the subgrade numerical model was established by FLAC3D software, and the effect of different types of grid-reinforced subgrade was analyzed. The results showed that the two-way geogrid has better reinforcement effect than the one-way geogrid due to the uniformity of the force $[6,7]$. Based on the practical engineering, $\mathrm{Lu}$ used the finite difference software to establish the numerical model of subgrade deformation 
treated by slope piles, analyzed the displacement of the top surface of the subgrade and the displacement of the foundation, and proposed a composite treatment scheme for the pile foundation in the soft soil foundation $[8,9]$. Petriaev et al. studied the stress-strain state of the subgrade using geogrid technology, relying on the mechanism of the reinforced subgrade soil, and the effect of different geogrid modulus on the deformation of the subgrade was proposed $[10,11]$. Sakleshpur et al. conducted large-scale direct shear test on the soft soil subgrade treated by geogrid and analyzed the effect of different grid laying schemes on the subgrade deformation. The optimum improvement scheme of treating soft soil subgrade with geogrid was put forward $[12,13]$. Gao et al. used the combination of explicit finite element method and time domain analysis, based on the viscoelastic theory, the stress and strain distribution of the subgrade using different geogrid layers and modulus were analyzed, and a geogrid laying scheme with superior seismic performance was proposed $[14,15]$. According to the characteristics of the geogrid in the rigid retaining wall, Jiang et al. used the Phase software to establish the numerical calculation model of the reinforced retaining wall. Based on the strength reduction method, the settlement of the subgrade and the stability coefficient of the retaining wall under different grid layout schemes were calculated. The optimal layout scheme of geogrid was proposed, and the superiority of the scheme was proved by centrifugal test $[16,17]$. Based on three-dimensional finite element analysis, Mousavi et al. obtained the geogrid tensile force and subgrade deformation in different positions under cyclic loading and proposed the optimal laying position of geogrid in the subgrade $[18,19]$.

Most research scholars focus on the differential settlement of subgrade treated by geogrid mainly in finite element numerical calculation software, laboratory model test, and field test and propose the optimal grid layout scheme for practical engineering. However, different working conditions have different requirements for differential settlement. In the actual design of geogrid, most of them are based on the previous engineering experience combined with the current situation of the road to develop the geogrid scheme, lacking uniform standards. Therefore, it is necessary to conduct a deep research on the related design and layout of geogrid in subgrade engineering. This paper innovatively applied the driving comfort index to the subgrade differential settlement control, calculated the correlation relationship of vertical acceleration and differential settlement of the human body at different speeds, and proposed the subgrade differential settlement control standard based on driving comfort. By establishing the finite element model of the cut to fill subgrade, the characteristics of differential settlement at the top surface of the subgrade under different geogrid laying positions, densities, and lengths were calculated and analyzed. The layout scheme of geogrid-treated subgrade differential settlement based on driving comfort was proposed, and the effectiveness of the scheme was verified by experiments.

\section{Mechanism Analysis}

2.1. Driving Comfort Indicator. The bumpiness of the car will increase the visual burden of the driver and the passenger. Likewise, it could also cause the vehicle to run unsteadily, making the passenger feel uncomfortable whether in the physical or psychological, and affecting the comfort of the human body.

Relevant studies have shown [20,21] that the discomfort caused by the previous vibration will aggravate the discomfort within 60 seconds after the human body is subjected to a high-amplitude vibration. When the two vibration intervals exceed $120 \mathrm{~s}$, the discomfort caused by the two vibrations basically does not affect each other, that is, the subjective discomfort caused by a large vibration will gradually disappear within $120 \mathrm{~s}$.

Referring to the relationship between human subjective feeling and acceleration proposed in the national standard GB/T13441.1-2007 [22], the control standard of driving comfort based on vertical acceleration is obtained as shown in Table 1.

2.2. Man-Vehicle-Road Coupling System Model. The human body comfort index is calculated based on the vertical acceleration [23] The two-degree-of-freedom human sitting posture model and the $1 / 4$ vehicle model are selected. Newton's second law can be used to obtain the $1 / 4$ vehicle model mathematical model:

$$
\begin{aligned}
& \left\{\begin{array}{l}
m_{s} \ddot{z}_{s}+c_{s}\left(\dot{z}_{s}-\dot{z}_{t}\right)+k_{s}\left(z_{s}-z_{t}\right)=0, \\
m_{t} \ddot{z}_{t}-c_{s}\left(\dot{z}_{s}-\dot{z}_{t}\right)-k_{s}\left(z_{s}-z_{t}\right)+k_{t}\left(z_{t}-z_{w}\right)+c_{t}\left(\dot{z}_{t}-\dot{z}_{w}\right)=0,
\end{array}\right. \\
& \quad m_{w} \ddot{z}_{w}-k_{t}\left(z_{t}-z_{w}\right)-c_{t}\left(\dot{z}_{t}-\dot{z}_{w}\right)+p_{t}=0,
\end{aligned}
$$

where $m_{s}$ is the suspension system quality; $m_{t}$ is the nonsuspension system quality; $m_{w}$ is the tire quality; $k_{s}$ is the suspension system stiffness; $k_{t}$ is the tire stiffness; $c_{s}$ is the suspension system damping; $c_{t}$ is the tire damping; $z_{s}$ is the suspension system vertical displacement; $z_{t}$ is the nonsuspension system vertical displacement; $z_{w}$ is the tire vertical displacement; and $p_{t}$ is the vehicle load on the road surface.

The two-degree-of-freedom human sitting posture model can be expressed as follows:

$$
m_{r} \ddot{z}_{w}+c_{r}\left(\dot{z}_{w}-\dot{z}_{s}\right)+k_{r}\left(z_{w}-z_{s}\right)=0
$$

where $m_{r}$ is the human body quality; $c_{r}$ is the damping; and $k_{r}$ is the stiffness.

The pavement structure is regarded as an elastic layered system. It is assumed that the materials in each layer of the pavement are elastic, homogeneous, and isotropic. The contact between the layers is completely continuous. The bottom of the structure is fixed and there is no lateral displacement. The finite element method is used to establish the pavement structural model, and the dynamic equation of the pavement structure is as follows:

$$
[m]\{\ddot{\delta}\}+[c]\{\dot{\delta}\}+[k]\{\delta\}=\{p\},
$$


TABLE 1: Driving comfort control standards.

\begin{tabular}{lcccc}
\hline Vertical acceleration $\alpha\left(\mathrm{m} / \mathrm{s}^{2}\right)$ & $\alpha<1.0$ & $1.0 \leq \alpha<1.6$ & $1.6 \leq \alpha<2.5$ & $\alpha \geq 2.5$ \\
\hline Human sense of comfort & Comfortable & Uncomfortable & Very uncomfortable & Extremely uncomfortable \\
\hline
\end{tabular}

where $[m],[c],[k]$ are the mass, stiffness, and damping matrix of the pavement structure; $\{\delta\},\{\dot{\delta}\}, \%\{\ddot{\delta} \%\}$ are the displacement, velocity, and acceleration vectors of the pavement structure; and $\{p\}$ is the load vector of the road surface.

The tire and the road surface are assumed in constant contact state, so the vertical displacement of the vehicle is equal to the vertical deformation of the road surface, and the vertical deformation of the road surface is composed of the flatness and the deformation under the external load. Therefore, the vertical displacement of the vehicle is given by

$$
Z_{w}=Z_{r}(x)+Z_{p}(x)=\sum_{n=1}^{N} A_{n} \phi_{n}(x)+Z_{p}(x)
$$

where $A_{n}$ is the generalized coordinates and $\phi_{n}(x)$ and $Z_{p}(x)$ are the vibration function and unevenness of the horizontal distance $x$ position of the pavement structure, respectively.

The dynamic equilibrium equation of the man-vehicleroad coupling system is obtained relying on the mathematical equation of the man-vehicle model, the vibration response equation of the pavement structure, and formula (4);

$$
\left\{\begin{array}{l}
{\left[\begin{array}{cc}
m_{s} & 0 \\
0 & m_{t}
\end{array}\right]\left\{\begin{array}{l}
\ddot{z}_{s} \\
\ddot{z}_{t}
\end{array}\right\}+\left[\begin{array}{cc}
c_{s} & -c_{s} \\
-c_{s} & c_{s}+c_{t}
\end{array}\right]\left\{\begin{array}{l}
\dot{z}_{s} \\
\dot{z}_{t}
\end{array}\right\}+\left[\begin{array}{cc}
k_{s} & -k_{s} \\
-k_{s} & k_{s}+k_{t}
\end{array}\right]\left\{\begin{array}{l}
\ddot{z}_{s} \\
\ddot{z}_{t}
\end{array}\right\}=\left\{k_{t}\left[\sum_{n=1}^{N} A_{n} \phi_{n}(x)+Z_{p}(x)\right]+c_{t}\left[\sum_{n=1}^{N} \dot{A}_{n} \phi_{n}(x)+\dot{Z}_{p}(x)\right]\right\}} \\
\ddot{A}_{n}+2 \xi_{n} \omega_{n} \dot{A}_{n}+\omega_{n}^{2} A_{n}=\phi_{n}(x)\left(k_{t} z_{t}+c_{t} \dot{z}_{t}+p_{s}\right)-\phi_{n}(x)\left\{k_{t}\left[\sum_{n=1}^{N} A_{n} \phi_{n}(x)+Z_{p}(x)\right]+c_{t}\left[\sum_{n=1}^{N} \dot{A}_{n} \phi_{n}(x)+\dot{Z}_{p}(x)\right]\right. \\
\left.-m_{w}\left[\sum_{n=1}^{N} \ddot{A}_{n} \phi_{n}(x)+\ddot{Z}_{p}(x)\right]\right\}
\end{array}\right.
$$

The abovementioned man-vehicle-road coupled system equations are a set of high-order second-order nonlinear differential equations, which are solved by MATLAB software. The equations can be used to obtain the displacement, velocity, and acceleration of the human body at any point.

\subsection{Finite Element Simulation Model}

2.3.1. Horizontal Cut to Fill Location Calculation Model. The model consists of three parts: roadbed filler, loess foundation, and geogrid, the Mohr-Coulomb plastic constitutive model was used to simulate the subgrade and foundation based on Abaqus software, and Truss (one-dimensional linear rod unit) was selected to establish the grating components. Embedded was used as the interaction between grid and soil, i.e., the grid is embedded in the subgrade. Both sides of the foundation were constrained in $x$-direction, and the ground base was also constrained in $y$ direction. The specific situation was designed according to the actual working conditions as shown in Figure 1.

In the calculation, the elastic constitutive model is adopted for each layer of the road surface. The parameters of the subgrade pavement material [24] are shown in Tables 2 and 3. Traffic load effects are simplified as half-wave sine loads, the driving load is the standard axle load BZZ-100, and the selection of the standard axle load is based on the $n=1,2, \ldots, N$.

"Code for Design of Highway Asphalt Pavements," that is, a single-axis load of two wheels of $100 \mathrm{KN}$ and a wheel ground pressure of $0.7 \mathrm{MPa}$. According to the equivalent principle of load stress, the double-circle uniform load is converted into a rectangular load. The width of the contact surface is $0.2 \mathrm{~m}$, and the load period is $2 \mathrm{~s}$.

The geogrid used for cut to fill subgrade is a two-way HDPE geogrid with a mesh size of $40 \mathrm{~mm} \times 36 \mathrm{~mm}$ and an ultimate tensile strength of $95 \mathrm{KN} / \mathrm{m}$. The geogrid parameters are shown in Table 4.

Use static, general analysis step; 2D planar component was used to build the model. When dividing gridding cells, the geogrid uses B21 unite cell, and the model was divided into multiple regular quadrilaterals and irregular polygon regions. The quadrilateral cell type is CPE8R, and the division of cell is shown in Figure 2.

\subsubsection{Longitudinal Cut to Fill Location Calculation Model.} The total length of subgrade model filling section was $15 \mathrm{~m}$, and the specific situation was designed according to the actual working conditions, as shown in Figure 3. The parameter setting method is the same as above.

2.3.3. Calculation Type Division. Using the above calculation model, the settlement distribution at the top surface of 


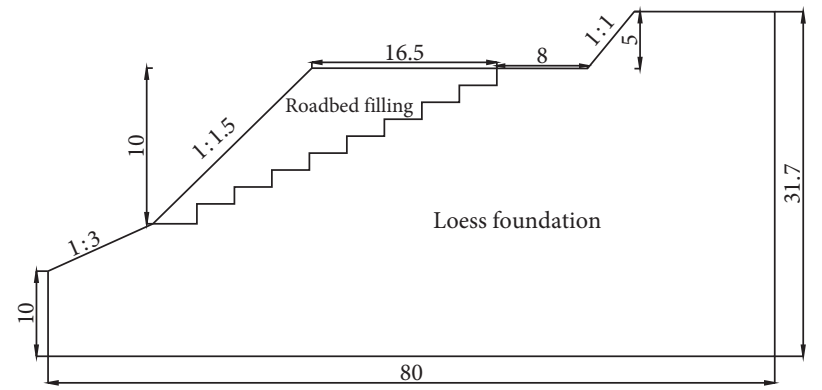

FIgURE 1: Calculation model for half-filled and half-cut subgrade (unit: m).

TABLE 2: Pavement structure and material parameters.

\begin{tabular}{lccccc}
\hline Horizon & Thickness $(\mathrm{m})$ & Material & Elastic modulus $(\mathrm{MPa})$ & $\mu$ & $\gamma\left(\mathrm{KN} / \mathrm{m}^{3}\right)$ \\
\hline Upper layer & 0.04 & Superpave-13 & 1400 & 0.35 & 24.2 \\
Mid-surface & 0.06 & Superpave-20 & 1300 & 0.3 & 24.2 \\
Binder course & 0.08 & ATB-25 & 1000 & 0.3 & 24.1 \\
Base & 0.35 & CTB & 1500 & 0.25 & 23.5 \\
Subbase & 0.2 & CTB & 1500 & 0.25 & 23.5 \\
Cushion & 0.2 & SG & 500 & 0.35 \\
\hline
\end{tabular}

TABLE 3: Soil parameters.

\begin{tabular}{lcccrc}
\hline Material types & Elastic modulus $(\mathrm{MPa})$ & $\mu$ & $\gamma\left(\mathrm{KN} / \mathrm{m}^{3}\right)$ & Cohesion $(\mathrm{kPa})$ & 45 \\
\hline Subgrade filling & 60 & 0.3 & 19.1 & 23 \\
Loess foundation & 52 & 0.3 & 19.8 & 48 & 25 \\
\hline
\end{tabular}

TABLE 4: Geogrid mechanical performance indicators.

\begin{tabular}{lcccccc}
\hline $\begin{array}{l}\text { Sectional area } \\
\left(\mathrm{m}^{2}\right)\end{array}$ & $\begin{array}{c}\text { Density }(\mathrm{kg} / \\
\left.\mathrm{m}^{3}\right)\end{array}$ & $\begin{array}{c}\text { Tensile strength } \\
(\mathrm{KN} / \mathrm{m})\end{array}$ & $\mu$ & $\begin{array}{c}\text { Maximal tensile } \\
\text { rate }(\%)\end{array}$ & $\begin{array}{c}\text { Tensile strength at 2\% tensile } \\
\text { rate }(\mathrm{KN} / \mathrm{m})\end{array}$ & $\begin{array}{c}\text { Tensile strength at 5\% tensile } \\
\text { rate }(\mathrm{KN} / \mathrm{m})\end{array}$ \\
\hline 0.00015 & 950 & 52.3 & 0.32 & 22.4 & 13.4 & 22.5 \\
\hline
\end{tabular}

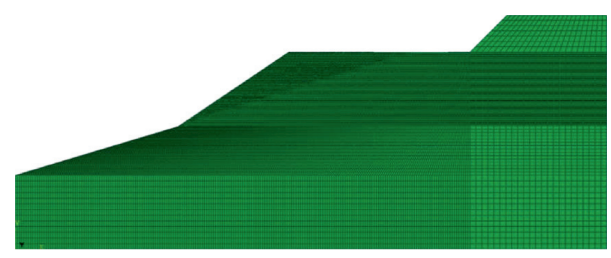

Figure 2: Computational model cell division.

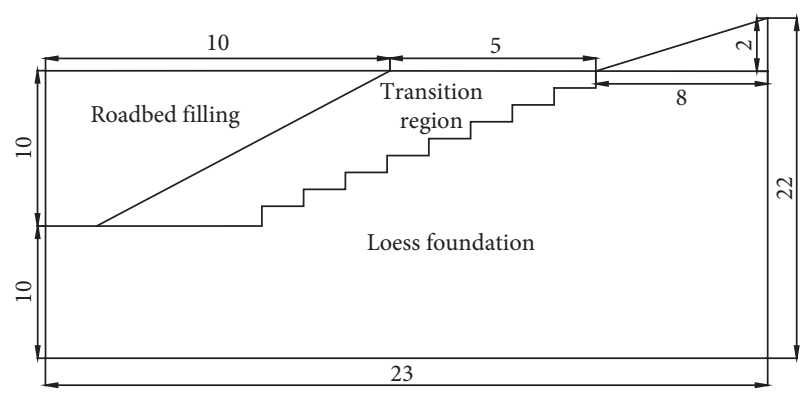

(a)

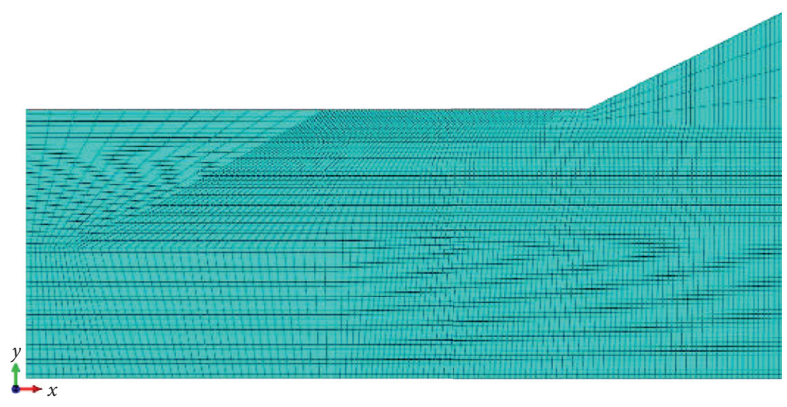

(b)

FIgURE 3: Calculation model and cell division of longitudinal half-filled and half-cut subgrade. (a) Schematic diagram of the calculation model (unit: m). (b) Cell division. 
the subgrade at the junction of longitudinal and transverse filling and excavation with different locations, densities, and lengths of the geogrid was calculated, respectively. The specific scheme is shown in Table 5.

\section{Subgrade Differential Settlement Control Standard Based on Driving Comfort}

In the operation process, the cut to fill subgrade would produce uneven settlement. When the uneven settlement was small, the longitudinal and transverse slopes of the road changed little, and the road surface structure did not crack, and the subgrade deformed in curve mode, as shown in Figure 4. This paper focuses on the differential settlement control of the subgrade under this deformation mode.

\subsection{Influence of Subgrade Differential Settlement Length on} Driving Comfort. According to the man-vehicle-road coupling system, the vertical acceleration of the human body in the curve mode of subgrade deformation was analyzed. The lengths of the differential settlement zone of the subgrade were $10 \mathrm{~m}$ and $20 \mathrm{~m}$, respectively, and the differential settlement values of the subgrade were $1 \mathrm{~cm}, 2 \mathrm{~cm}, 5 \mathrm{~cm}$, and $8 \mathrm{~cm}$ respectively, and the car speed was taken as $100 \mathrm{~km} / \mathrm{h}$. The calculation results are shown in Table 6 .

In the case of the same differential settlement of the subgrade, the length of the differential settlement of the subgrade would cause a large difference in the subjective comfort. The vertical acceleration of the human body decreased significantly with the increase of settlement zone length, which was about $50 \% \sim 60 \%$. It could be seen that the length of the differential settlement area of the subgrade had a vital influence on the subjective comfort of the human body. Thereby, to better reduce the discomfort caused by the uneven settlement of the subgrade, the length of the differential settlement zone of subgrade should be increased as far as possible within the allowable range of conditions.

3.2. Influence of Vehicle Speed and Subsidence Value on Driving Comfort. Different vehicle speeds and subgrade differential settlement values are selected, and the vertical acceleration of the human body is calculated according to the man-vehicle-road coupling system when the settlement zone length is $10 \mathrm{~m}$. The calculation results are shown in Table 7.

The analysis of Figure 5 shows that when other conditions are the same, the greater the vehicle speed, the greater the vertical acceleration of the human body caused by the differential settlement of the subgrade. The vertical acceleration of the human body caused by differential settlement of subgrade increased by $14.8 \% \sim 41.2 \%$ with the increase of $20 \mathrm{~km} / \mathrm{h}$ in vehicle speed, that is, vehicle speed has a greater impact on driving comfort; when the vehicle speed is the same, the growth rate of the vertical acceleration of the human body is relatively small when the differential settlement of the subgrade is within $2 \mathrm{~cm}$, and the vertical acceleration of the human body increases significantly when the differential settlement is more than $2 \mathrm{~cm}$. It can be seen from the figure that the impacts of subgrade subsidence value and vehicle speed on human comfort are great, and the impact of subsidence value on human comfort is more significant.

3.3. Subgrade Differential Settlement Control Standard. According to the calculation results of the vertical acceleration of the human body at different vehicle speeds and different settlement zone lengths above, multiple regression equations are used to fit their correlation, and the results are shown in Figure 6.

According to the correlation shown in Table 8, the differential settlement corresponding to the vertical acceleration of the human body at different driving speeds could be calculated. Then, combined with the human comfort index, the differential settlement of the subgrade whose vertical acceleration of human body was $1.0 \mathrm{~m} / \mathrm{s}^{2}, 1.6 \mathrm{~m} / \mathrm{s}^{2}$, and $2.5 \mathrm{~m} / \mathrm{s}^{2}$ was calculated, respectively. This is the differential settlement control standard based on driving comfort in the curve mode of subgrade deformation. The specific indicators are shown in Table 9.

\section{Geogrid Layout Scheme Based on Driving Comfort}

\subsection{Analysis of Treatment Effect at the Horizontal Cut to Fill Location}

4.1.1. Deformation of Subgrade in Different Positions of Geogrid Laying. The settlement distribution at the top surface of the subgrade at the horizontal cut to fill subgrade was calculated as shown in Figure 7 (the origin of abscissa in Figures 7-12 is the left edge at the top of the subgrade, and the positive direction points to the side of the cut subgrade).

It can be seen from Figure 7 that when geogrids were arranged in the upper $1 / 3$ range of the subgrade, the differential settlement at the top of the subgrade was the smallest, with a value of $8.1 \mathrm{~cm}$. When geogrids were arranged in the range of 7-10 $\mathrm{m}$ below the top of the subgrade, the differential settlement at the top of the pavement was the largest, with a value of $14.5 \mathrm{~cm}$. Geogrid layout ranges moved $1 / 3$ depth to the lower part of the subgrade, and differential settlement on the top of the subgrade increased by $18.8 \% \sim 39.3 \%$. The closer the geogrid layout ranges to the upper part of the subgrade, the larger the differential settlement reduction on the top, and the more obvious the treatment effect was.

\subsubsection{Deformation of Subgrade with Different Grid Laying} Densities. The settlement distribution at the top surface of the subgrade at the horizontal cut to fill subgrade was calculated as shown in Figure 8.

It can be seen from Figure 8 that after the geogrid was added to the cut to fill subgrade, the differential settlement at the top surface of the subgrade was significantly reduced. For each $0.5 \mathrm{~m}$ increase in the grid spacing, the differential settlement of the top surface of the subgrade will increase by $13.3 \% \sim 33.3 \%$. When the interval between adjacent grids was 
TABLE 5: Finite element calculation method for vertical and horizontal cut to fill location.

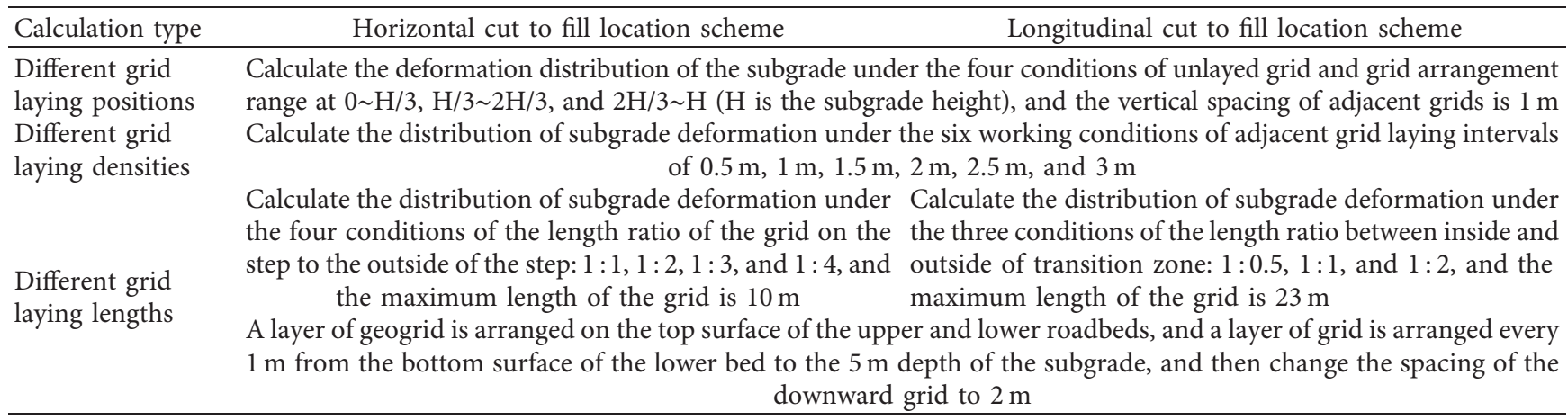

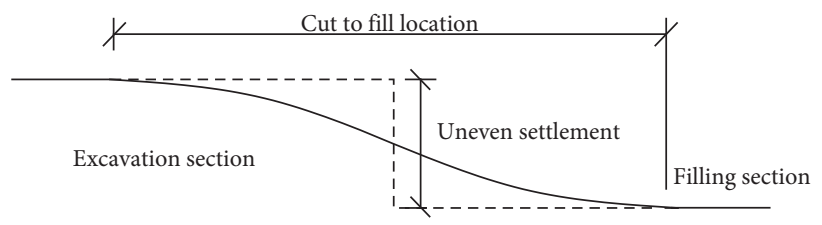

Figure 4: Subgrade curve deformation.

TABLE 6: Vertical acceleration under different subgrade differential settlement length.

\begin{tabular}{lccc}
\hline Subgrade differential settlement zone length $(\mathrm{m})$ & \multicolumn{2}{c}{$\begin{array}{c}\text { Vertical acceleration of the human body under different subgrade } \\
\text { differential settlement length }\left(\mathrm{m} / \mathrm{s}^{2}\right)\end{array}$} \\
\hline 10 & $\begin{array}{r}1 \mathrm{~cm} \\
2 \mathrm{~cm}\end{array}$ & 1.0 & 2.9 \\
20 & 0.4 & 0.4 & 5.5 \\
\hline
\end{tabular}

TABLe 7: Maximum vertical acceleration of the human body when the settlement zone length is $10 \mathrm{~m}$.

\begin{tabular}{|c|c|c|c|c|c|}
\hline \multirow{2}{*}{ Differential settlement $(\mathrm{cm})$} & \multicolumn{5}{|c|}{ Maximum vertical acceleration of the human body $\left(\mathrm{m} / \mathrm{s}^{2}\right)$} \\
\hline & $120 \mathrm{~km} / \mathrm{h}$ & $100 \mathrm{~km} / \mathrm{h}$ & $80 \mathrm{~km} / \mathrm{h}$ & $60 \mathrm{~km} / \mathrm{h}$ & $40 \mathrm{~km} / \mathrm{h}$ \\
\hline 1 & 0.6 & 0.4 & 0.2 & 0.1 & 0.1 \\
\hline 2 & 1.1 & 0.8 & 0.6 & 0.4 & 0.2 \\
\hline 5 & 3.2 & 2.7 & 2.3 & 1.9 & 1.6 \\
\hline 8 & 6.1 & 5.3 & 4.7 & 4.2 & 3.7 \\
\hline
\end{tabular}

$0.5 \mathrm{~m}$, the differential settlement at the top surface of the subgrade was $1.1 \mathrm{~cm}$, which was $86.1 \%$ lower than that when no geogrid was applied; when the interval between adjacent grids increased from $1 \mathrm{~m}$ to $1.5 \mathrm{~m}$, the differential settlement of the subgrade increased greatly, and the growth rate could reach $33.3 \%$. In other words, the treatment effect would be significantly improved when the grid spacing was controlled within $1 \mathrm{~m}$.

The geogrid laying density has an important influence on controlling the uneven deformation of the cut to fill subgrade. When the grid spacing was less than $1 \mathrm{~m}$, the differential settlement rate of the subgrade was small, and the benefit of the increase of the grid density was gradually reduced. When designing the geogrid laying scheme, a grid laying scheme in which the upper part of the subgrade was denser and the lower part was sparse could be used.
4.1.3. Deformation of Subgrade with Different Grid Laying Lengths. The settlement distribution at the top surface of the subgrade at the horizontal cut to fill subgrade was calculated as shown in Figure 9.

It can be seen from Figure 9 that in the same circumstances, the differential settlement value of the top surface of the cut to fill subgrade decreased with the increase of geogrid length in subgrade. This is because the settlement on the side of the filling subgrade was large, and the settlement near the edge of the subgrade was also larger, so increasing the length of the fillet grid could enhance the integrity of the subgrade and reduce the settlement of the fill subgrade; the length of the grid outer of the step was doubled compared to the length of the grid on the step, and the differential settlement at the top surface of the subgrade was reduced by $5.6 \%$ $23.1 \%$. Increasing the length of the outer grid of the step 


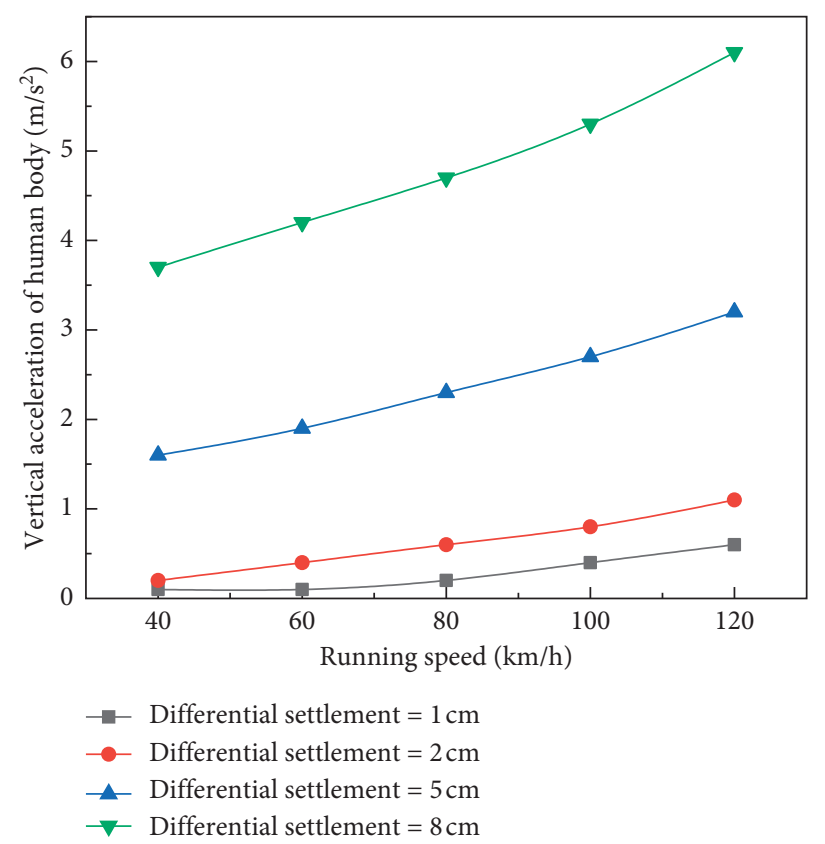

(a)

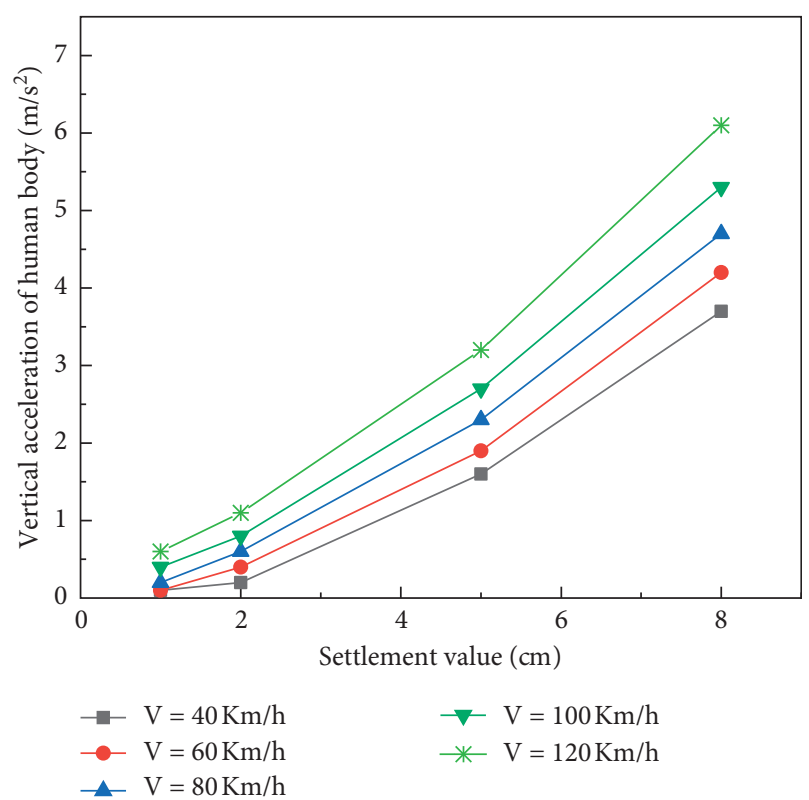

(b)

FIgURE 5: The relationship between the maximum vertical acceleration of the human body with the speed and subsidence. (a) Different running speeds and (b) different subsidence values.

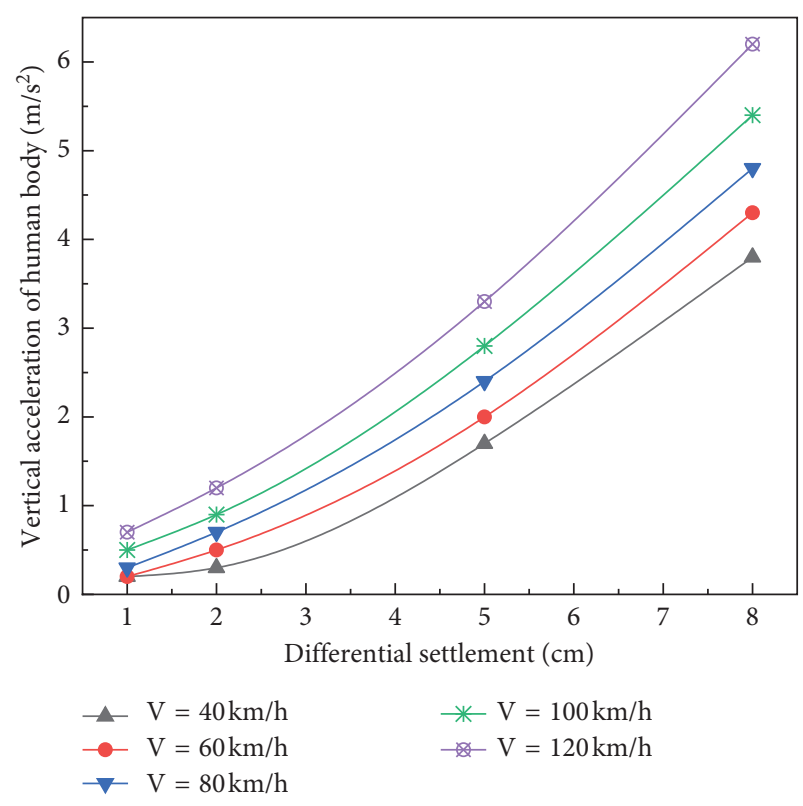

(a)

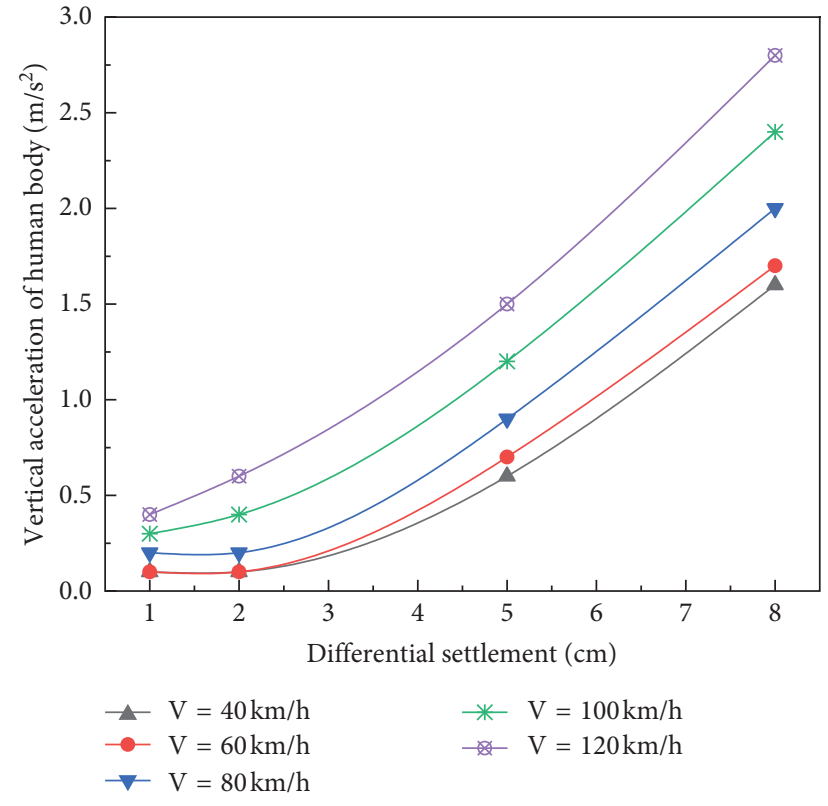

(b)

FiguRE 6: Correlation curve between maximum vertical acceleration of the human body and differential settlement value. (a) Differential settlement length $10 \mathrm{~m}$ and (b) differential settlement length $20 \mathrm{~m}$.

could effectively control the differential settlement at the top surface of the subgrade; compared with sublaying geogrid with subgrade depth below $5 \mathrm{~m}$, full-laying geogrid could reduce the differential settlement of the top surface of the subgrade by $5.4 \%$ to $7.8 \%$. Therefore, reducing the length of the outer step of the grid in the deeper part of the subgrade had little effect on the differential settlement. So, when designing the geogrid laying scheme, the length of the geogrid in the embankment could be designed to be gradually reduced from top to bottom. 
TABLE 8: Correlation between maximum vertical acceleration and differential settlement value.

\begin{tabular}{lccc}
\hline Vehicle speed $(\mathrm{km} / \mathrm{h})$ & Differential settlement value $(\mathrm{m})$ & Fitting relationship & Correlation coefficient \\
\hline \multirow{2}{*}{120} & 10 & $S(a)=0.0455 a^{2}+0.3776 a+0.2715$ & 0.9987 \\
& 20 & $S(a)=0.0227 a^{2}+0.1388 a+0.2358$ & 0.9995 \\
100 & 10 & $S(a)=0.0424 a^{2}+0.3215 a+0.117$ & 0.9997 \\
& 20 & $S(a)=0.0258 a^{2}+0.0715 a+0.1836$ & 0.9982 \\
80 & 10 & $S(a)=0.0394 a^{2}+0.2888 a-0.0309$ & 0.9993 \\
& 20 & $S(a)=0.0288 a^{2}+0.0042 a+0.1315$ & 0.9976 \\
60 & 10 & $S(a)=0.0455 a^{2}+0.1776 a+0.0285$ & 0.9999 \\
40 & 20 & $S(a)=0.0273 a^{2}-0.0121 a+0.0576$ & 0.9995 \\
& 10 & $S(a)=0.0485 a^{2}+0.087 a+0.0127$ & 0.9991 \\
\hline
\end{tabular}

TABle 9: Differential settlement control standards based on driving comfort.

\begin{tabular}{|c|c|c|c|c|c|c|c|c|}
\hline \multirow{3}{*}{ Vehicle speed $(\mathrm{km} / \mathrm{h})$} & \multicolumn{8}{|c|}{ Different comfort level differential settlement control standards $(\mathrm{cm})$} \\
\hline & \multicolumn{4}{|c|}{ Differential settlement length $10 \mathrm{~m}$} & \multicolumn{4}{|c|}{ Differential settlement length $20 \mathrm{~m}$} \\
\hline & Excellent & Good & Poor & Worse & Excellent & Good & Poor & Worse \\
\hline 120 & $S<1.6$ & $1.6 \leq \mathrm{S}<2.4$ & $2.4 \leq \mathrm{S}<4.2$ & $S \geq 4.2$ & $\mathrm{~S}<3.3$ & $3.3 \leq \mathrm{S}<5.2$ & $5.2 \leq \mathrm{S}<7.3$ & $S \geq 7.3$ \\
\hline 100 & $S<2.2$ & $2.2 \leq \mathrm{S}<3.1$ & $3.1 \leq \mathrm{S}<4.9$ & $S \geq 4.9$ & $S<4.2$ & $4.2 \leq \mathrm{S}<5.9$ & $5.9 \leq \mathrm{S}<8.2$ & $S \geq 8.2$ \\
\hline 80 & $\mathrm{~S}<2.4$ & $2.4 \leq \mathrm{S}<3.6$ & $3.6 \leq \mathrm{S}<5.3$ & $S \geq 5.3$ & $S<5.2$ & $5.2 \leq \mathrm{S}<6.8$ & $6.8 \leq \mathrm{S}<8.8$ & $S \geq 8.8$ \\
\hline 60 & $\mathrm{~S}<3.0$ & $3.0 \leq \mathrm{S}<4.1$ & $4.1 \leq \mathrm{S}<5.8$ & $S \geq 5.8$ & $S<5.9$ & $5.9 \leq \mathrm{S}<7.6$ & $7.6 \leq \mathrm{S}<9.3$ & $S \geq 9.3$ \\
\hline 40 & $S<3.5$ & $3.5 \leq \mathrm{S}<4.8$ & $4.8 \leq \mathrm{S}<6.3$ & $S \geq 6.3$ & $S<6.2$ & $6.2 \leq \mathrm{S}<7.9$ & $7.9 \leq \mathrm{S}<9.6$ & $S \geq 9.6$ \\
\hline
\end{tabular}

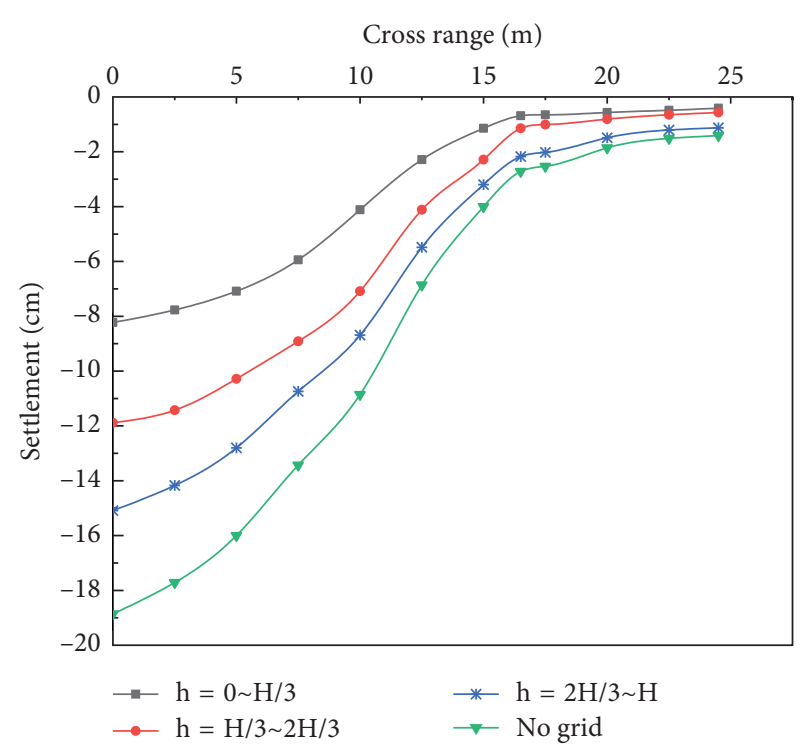

FIGURE 7: Settlement of the top surface of the subgrade at different grid laying locations.

\subsection{Analysis of Treatment Effect at the Longitudinal Cut to Fill Location}

4.2.1. Deformation of Subgrade in Different Positions of Geogrid Laying. The settlement distribution at the top surface of the subgrade at the longitudinal cut to fill subgrade was calculated as shown in Figure 10.

It can be seen from Figure 10 that when geogrids were arranged in the upper $1 / 3$ range of the subgrade, the differential settlement at the top of the subgrade was the smallest, with a value of $8.5 \mathrm{~cm}$. When geogrids were

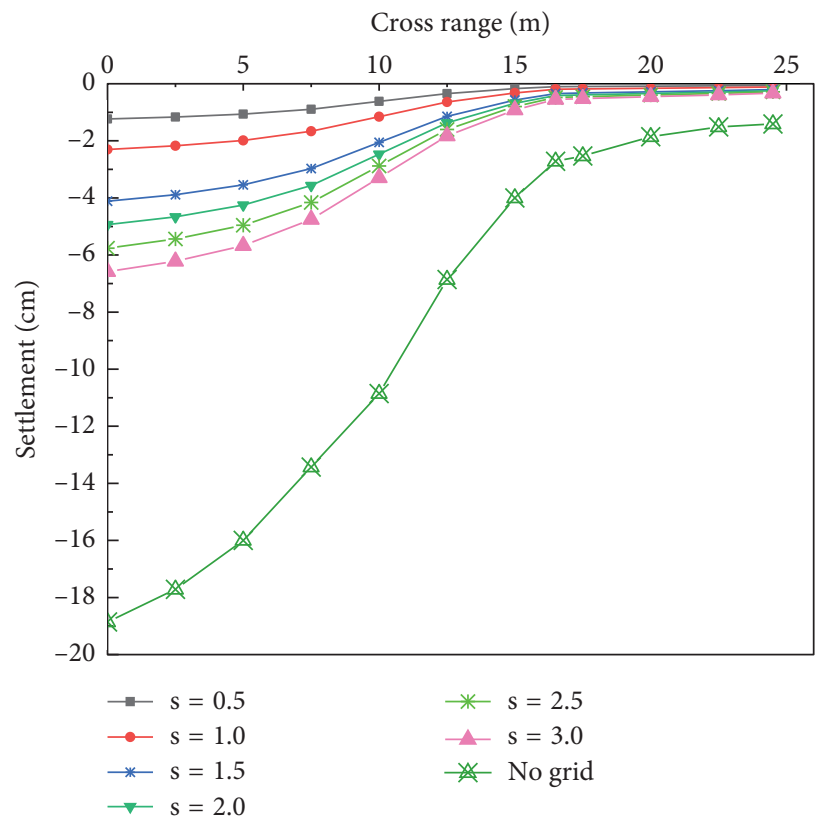

FIGURE 8: Settlement of the top surface of the subgrade at different grid laying densities.

arranged in the range of $7-10 \mathrm{~m}$ below the top of the subgrade, the differential settlement at the top of the pavement was the largest, with a value of $15.7 \mathrm{~cm}$. The effect of laying geogrids on the upper part of filling-excavation junction subgrade was better than that of laying geogrids on the lower part; the geogrids laying range moved $1 / 3$ depth to the lower part of the subgrade, and the differential settlement of the top of the subgrade increased by about $14.3 \%-32.1 \%$. The closer the grids laying range to the upper part of the 


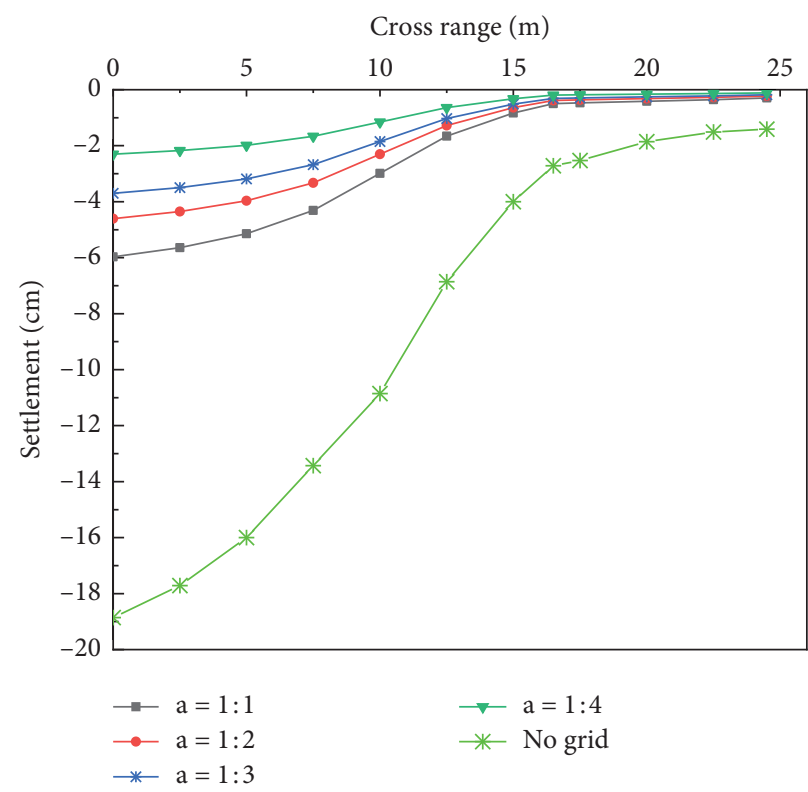

(a)

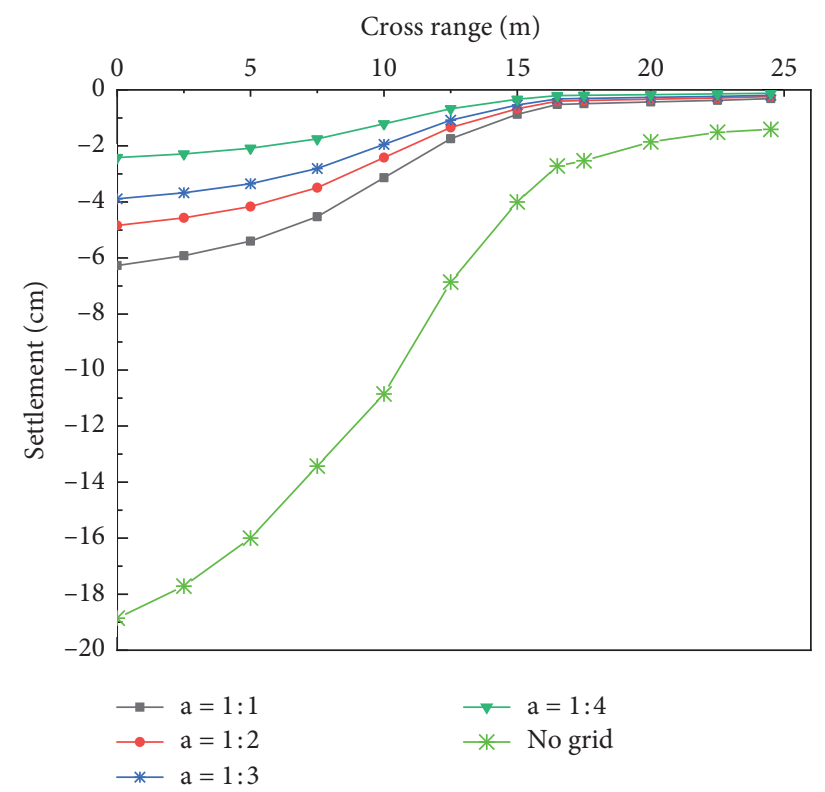

(b)

FIGURE 9: Settlement of the top surface of the subgrade at different grid laying lengths. (a) Full-laying grille with a subgrade depth below $5 \mathrm{~m}$. (b) Sublaying grille with a subgrade depth below $5 \mathrm{~m}$.

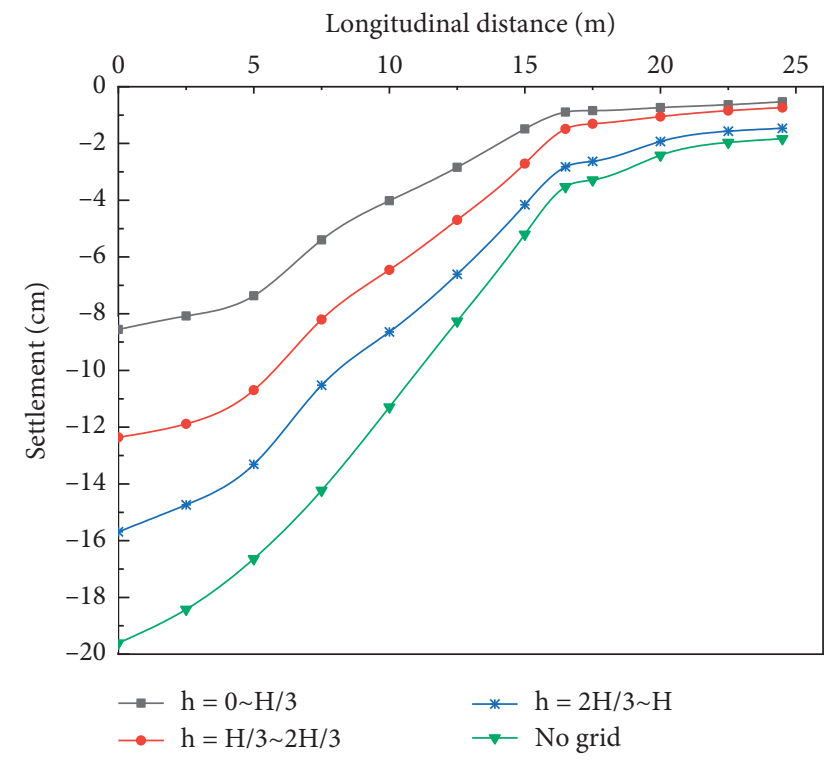

FIGURE 10: Settlement of the top surface of the subgrade at different grid laying locations.

subgrade, the greater the differential settlement of the top, the more obvious the improvement of the treatment effect is.

\subsubsection{Deformation of Subgrade with Different Geogrid Laying} Densities. The settlement distribution of the top surface of the subgrade at the longitudinal cut to fill subgrade was calculated as shown in Figure 11.

It can be seen from Figure 11 that after the geogrid was added to the subgrade at the cut to fill location, the differential settlement at the top surface of the subgrade was

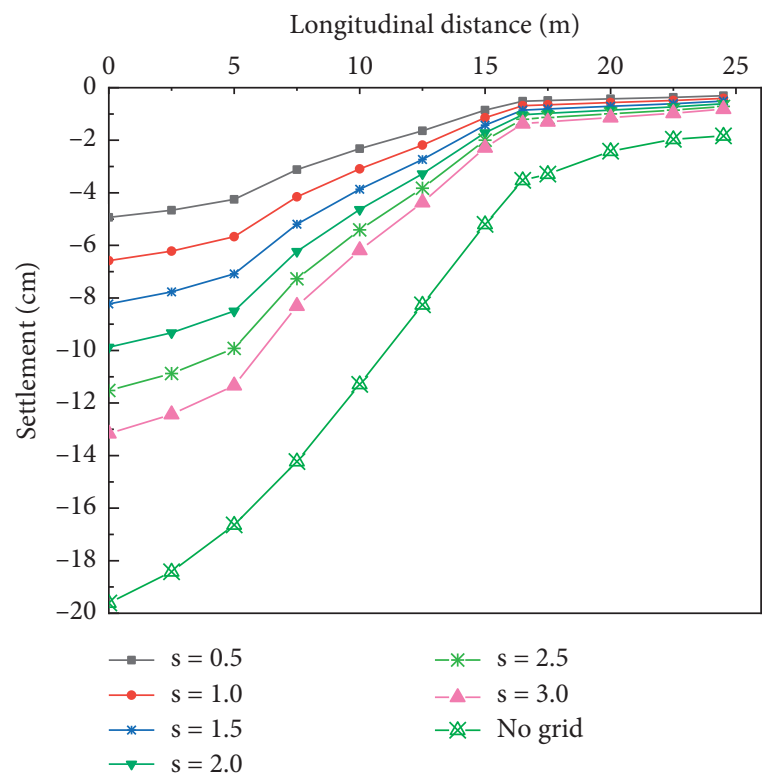

Figure 11: Settlement of the top surface of the subgrade at different grid laying densities.

significantly reduced. For each $0.5 \mathrm{~m}$ increase in the grid spacing, the differential settlement of the top surface of the subgrade would increase by $10.5 \% \sim 28.9 \%$. When the interval between adjacent geogrids was $0.5 \mathrm{~m}$, the differential settlement of the top surface of the subgrade was $4.6 \mathrm{~cm}$, which was $83.6 \%$ lower than that when no reinforcement was applied; the geogrid laying density had an important influence on controlling the uneven deformation of the subgrade at the cut to fill location. Especially, the deformation of the upper part of the subgrade was very sensitive 


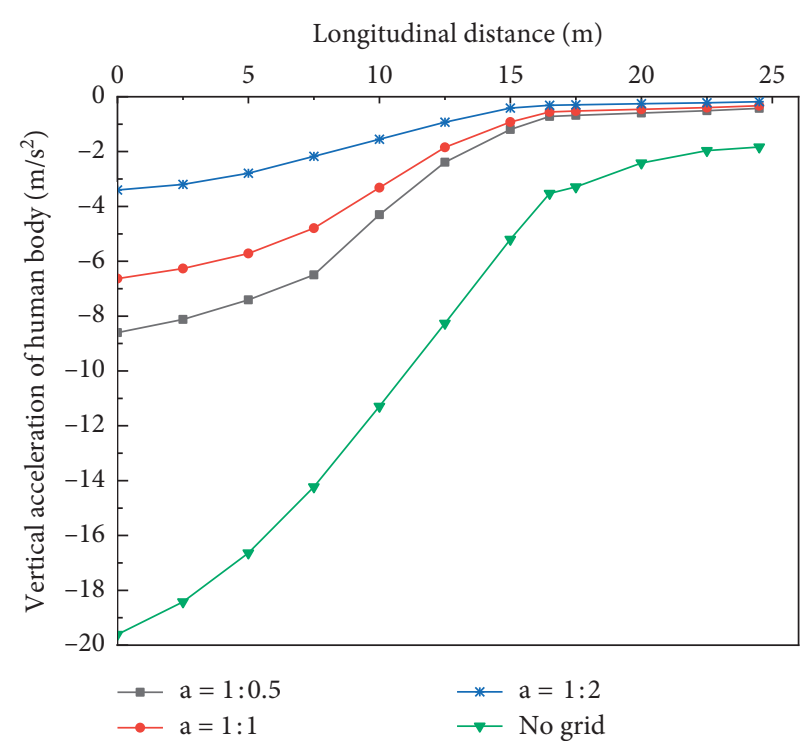

Figure 12: Settlement of the top surface of the subgrade at different grid laying lengths.

to the change of the geogrid density. In the design of geogrid laying scheme, the more dense upper part of subgrade and sparse lower part of subgrade can be used.

4.2.3. Deformation of Subgrade with Different Grid Laying Lengths. The settlement distribution of the top surface of the subgrade at the longitudinal cut to fill subgrade was calculated as shown in Figure 12.

As shown in Figure 12, when the outer length of the transition zone of the subgrade was doubled compared with the length of the transition zone, the differential settlement of the top surface of the subgrade was reduced by $4.7 \%$ $19.8 \%$. It can be seen that increasing the length of the outer geogrid in the transition zone can effectively control the differential settlement on the top of the subgrade, but increasing the length of the outer geogrid in the deeper part of the subgrade had no significant effect on the differential settlement control.

4.3. Geogrid Layout Scheme. The above research shows that when the geogrid is used to treat the uneven settlement of the horizontal and longitudinal cut to fill subgrade, the main factor affecting the treatment effect was the laying position, followed by the length and layout density of the grid. Therefore, the geogrid laying scheme should adopt the method that the upper part is denser and the lower part is sparse, and the length of the grid can be designed by the way of gradually decreasing from top to bottom. According to the requirements of differential settlement for driving comfort in different vehicle speeds, combined with the effect of geogrid density and length change on differential settlement, the geogrid layout schemes based on the driving comfort of horizontal and longitudinal cut to fill subgrade are obtained.

\subsubsection{Horizontal Cut to Fill Location Geogrid Layout Scheme}

(1) When the high-filled subgrade $\mathrm{H} \leq 20 \mathrm{~m}$, a layer of geogrid was arranged at the top surface of the upper and lower roadbeds and the bottom surface of the lower subgrade. The length ratio of the filling and excavating section is $1: 1$, and the total length of the grid was $L_{1}$; from the bottom of the lower subgrade, a layer of grid is laid every $h_{1}$, a total of $n_{1}$ layers are laid, and the length of the grid is $L_{2}$; then a layer of grid is laid down every $h_{2}$ in down position, a total of $n_{2}$ layers are laid, and the length of the grid is $L_{3}$.

(2) When the high-filled subgrade $\mathrm{H}>20 \mathrm{~m}$, the grid should be laid in accordance with the provisions of (1). In addition, $2 \sim 3$ geogrids shall be added in the range of subgrade depth $\mathrm{H} / 3 \sim 2 \mathrm{H} / 3$, and the total length of the grid is $L_{3}$.

The grid layout scheme is shown in Figure 13, and the paving parameters are shown in Table 10.

\subsubsection{Longitudinal Cut to Fill Location Geogrid Layout Scheme}

(1) When the high-filled subgrade $\mathrm{H} \leq 20 \mathrm{~m}$, a layer of geogrid is arranged on the top surface of the upper and lower subgrades and the bottom surface of the lower subgrade. The length of the grid section is $L_{\mathrm{w}}$, and the length of the filling section is $\left(L_{t}+L\right)$, where $L$ is the length of the transition section; from the bottom of the lower bed, a layer of grid is laid every $h_{1}$, a total of $n_{1}$ layers are laid, the length of the grid is $\left(L_{1}+L\right)$; then a layer of grid is laid down every $h_{2}$ in down position, a total of $n_{2}$ layers are laid, and the length is $\left(L_{2}+L\right)$.

(2) When the high-filled subgrade $\mathrm{H}>20 \mathrm{~m}$, the grid should be laid in accordance with the provisions of (1). In addition, 2 3 geogrids shall be added in the range of subgrade depth $\mathrm{H} / 3 \sim 2 \mathrm{H} / 3$, and the total length of the grid is $\left(L_{2}+L\right)$.

The grid layout scheme is shown in Figure 14, and the paving parameters are shown in Table 11.

\section{Design Example}

Two test sections were selected in Weiwu Expressway (Gansu, China), which are the horizontal cut to fill subgrade $(\mathrm{K} 227+250 \sim \mathrm{K} 227+350)$ and the longitudinal cut to fill subgrade $(\mathrm{K} 221+370 \sim \mathrm{K} 221+420)$.

5.1. The Horizontal Cut to Fill Subgrade. The original design scheme: two layers of bidirectional geogrid were laid on the top of the upper and lower subgrades, and one layer of geogrid was laid on the bottom of the lower subgrade. The length of the geogrid was $10 \mathrm{~m}$, and the length of the filling and excavating section was $5 \mathrm{~m}$.

The improvement scheme: a bidirectional geogrid was laid on the top and bottom of the upper and lower subgrades, 


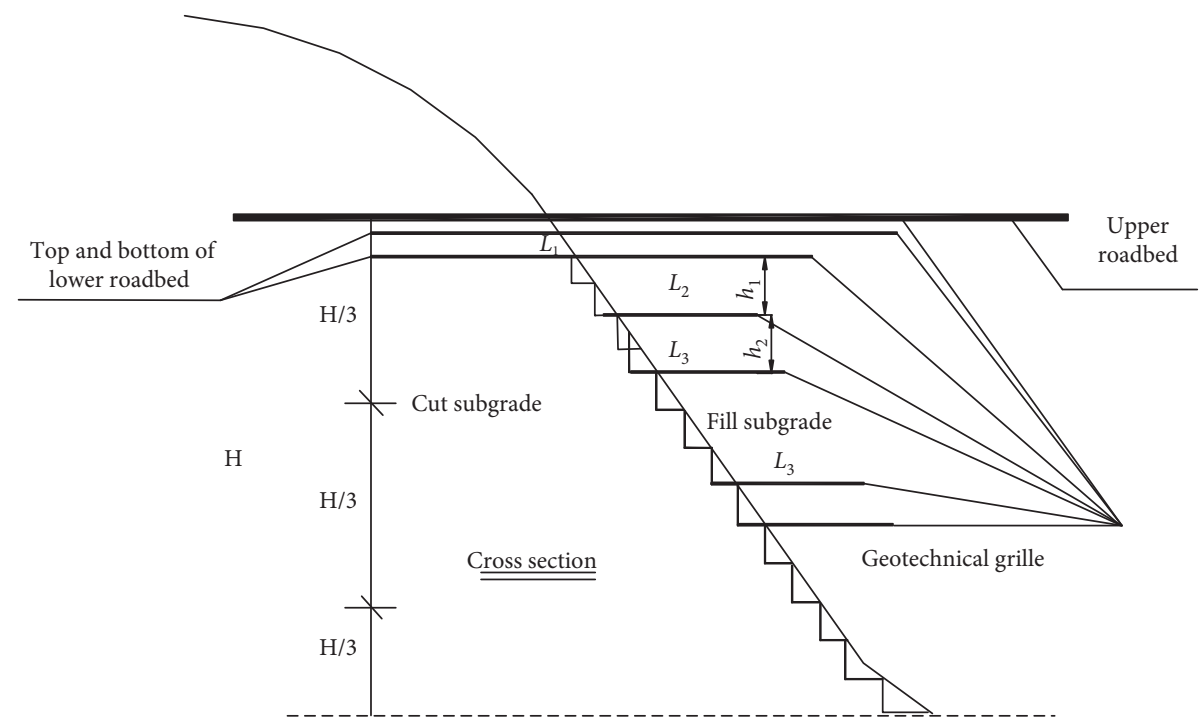

FIgURE 13: Schematic diagram of geogrid layout scheme for longitudinal cut to fill location.

TABLE 10: Geogrid paving scheme parameters for longitudinal cut to fill location.

\begin{tabular}{|c|c|c|c|c|c|c|c|c|}
\hline Vehicle speed $(\mathrm{km} / \mathrm{h})$ & Distribution distance of differential settlement $l(\mathrm{~m})$ & $L_{1}(\mathrm{~m})$ & $L_{2}(\mathrm{~m})$ & $L_{3}(\mathrm{~m})$ & $h_{1}(\mathrm{~m})$ & $h_{2}(\mathrm{~m})$ & $n_{1}$ & $n_{2}$ \\
\hline & $l \leq 2000$ & 20 & 10 & 8 & 1 & 1.5 & 2 & 2 \\
\hline \multirow[t]{3}{*}{120} & $2000<l \leq 4000$ & 15 & 8 & 6 & 1.5 & 2 & 2 & 1 \\
\hline & $l>4000$ & 12 & 6 & 5 & 1.5 & 2 & 2 & 0 \\
\hline & $l \leq 1670$ & 15 & 8 & 6 & 1 & 1.5 & 2 & 2 \\
\hline \multirow[t]{3}{*}{100} & $1670<l \leq 3340$ & 12 & 8 & 6 & 1.5 & 2 & 2 & 1 \\
\hline & $l>3340$ & 10 & 6 & 5 & 1.5 & 2 & 2 & 0 \\
\hline & $l \leq 1330$ & 10 & 6 & 6 & 1 & 1.5 & 2 & 2 \\
\hline \multirow[t]{3}{*}{80} & $1330<l \leq 2660$ & 8 & 6 & 5 & 1.5 & 2 & 2 & 1 \\
\hline & $l>2660$ & 6 & 5 & 4 & 1.5 & 2 & 2 & 0 \\
\hline & $l \leq 1000$ & 8 & 6 & 5 & 1 & 1.5 & 2 & 2 \\
\hline \multirow[t]{3}{*}{60} & $1000<l \leq 2000$ & 6 & 5 & 4 & 1.5 & 2 & 2 & 1 \\
\hline & $l>2000$ & 5 & 4 & 3 & 1.5 & 2 & 2 & 0 \\
\hline & $l \leq 670$ & 6 & 5 & 4 & 1 & 1.5 & 2 & 2 \\
\hline \multirow[t]{2}{*}{40} & $670<l \leq 1340$ & 5 & 4 & 3 & 1.5 & 2 & 2 & 1 \\
\hline & $l>1340$ & 4 & 3 & 3 & 1.5 & 2 & 2 & 0 \\
\hline
\end{tabular}

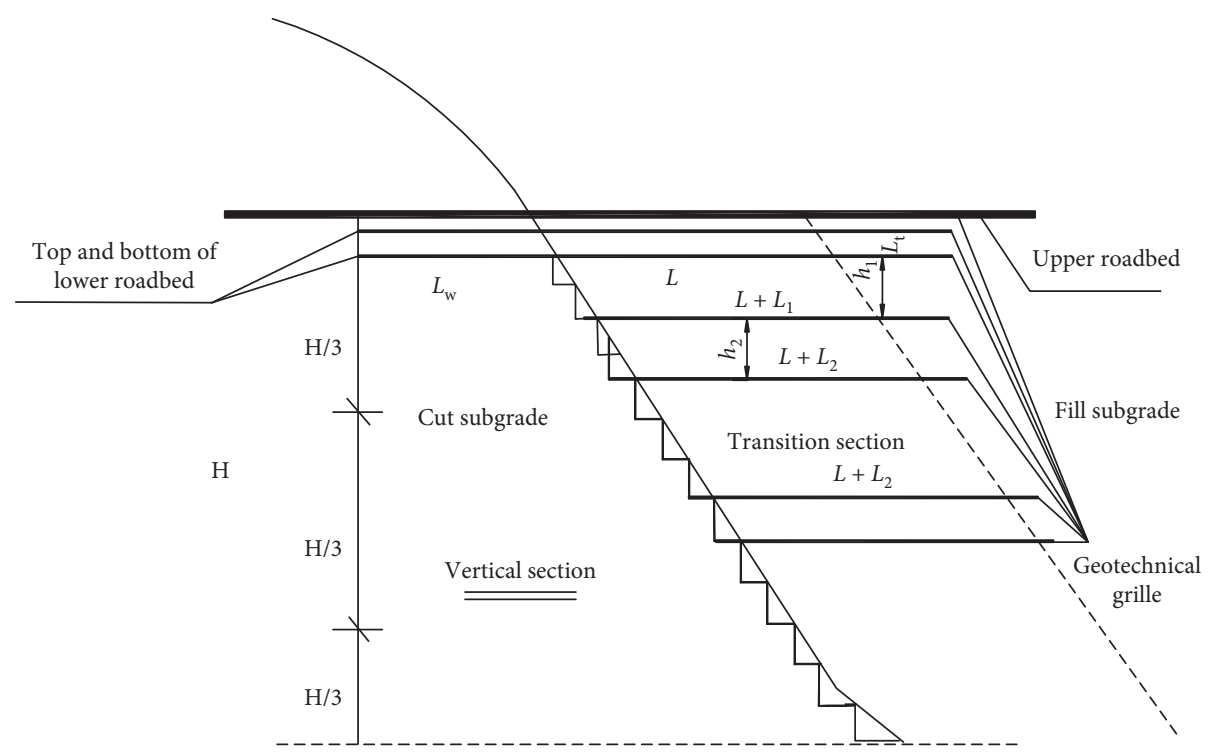

FIGURE 14: Schematic diagram of geogrid layout scheme for horizontal cut to fill location. 
TABLE 11: Geogrid paving scheme parameters for horizontal cut to fill location.

\begin{tabular}{|c|c|c|c|c|c|c|c|c|c|}
\hline Vehicle speed $(\mathrm{km} / \mathrm{h})$ & Distribution distance of differential settlement $l(\mathrm{~m})$ & $L_{\mathrm{w}}(\mathrm{m})$ & $L_{\mathrm{t}}(\mathrm{m})$ & $L_{1}(\mathrm{~m})$ & $L_{2}(\mathrm{~m})$ & $h_{1}(\mathrm{~m})$ & $h_{2}(\mathrm{~m})$ & $n_{1}$ & $\overline{n_{2}}$ \\
\hline & $l \leq 2000$ & 10 & 8 & 10 & 8 & 1 & 1.5 & 2 & 2 \\
\hline \multirow[t]{3}{*}{120} & $2000<l \leq 4000$ & 8 & 8 & 8 & 6 & 1.5 & 2 & 2 & 1 \\
\hline & $l>4000$ & 8 & 5 & 6 & 5 & 1.5 & 2 & 2 & 0 \\
\hline & $l \leq 1670$ & 10 & 8 & 8 & 6 & 1 & 1.5 & 2 & 2 \\
\hline \multirow[t]{3}{*}{100} & $1670<l \leq 3340$ & 8 & 8 & 6 & 5 & 1.5 & 2 & 2 & 1 \\
\hline & $l>3340$ & 8 & 5 & 5 & 4 & 1.5 & 2 & 2 & 0 \\
\hline & $l \leq 1330$ & 10 & 8 & 6 & 5 & 1 & 1.5 & 2 & 2 \\
\hline \multirow[t]{3}{*}{80} & $1330<l \leq 2660$ & 8 & 8 & 5 & 4 & 1.5 & 2 & 2 & 1 \\
\hline & $1>2660$ & 8 & 5 & 4 & 3 & 1.5 & 2 & 2 & 0 \\
\hline & $l \leq 1000$ & 10 & 8 & 5 & 4 & 1 & 1.5 & 2 & 2 \\
\hline \multirow[t]{3}{*}{60} & $1000<l \leq 2000$ & 8 & 8 & 4 & 3 & 1.5 & 2 & 2 & 1 \\
\hline & $l>2000$ & 8 & 5 & 3 & 3 & 1.5 & 2 & 2 & 0 \\
\hline & $l \leq 670$ & 10 & 8 & 4 & 3 & 1 & 1.5 & 2 & 2 \\
\hline \multirow[t]{2}{*}{40} & $670<l \leq 1340$ & 8 & 8 & 3 & 3 & 1.5 & 2 & 2 & 1 \\
\hline & $l>1340$ & 8 & 5 & 3 & 2 & 1.5 & 2 & 2 & 0 \\
\hline
\end{tabular}

the length of which was $8 \mathrm{~m}$ and the length of filling and excavating section is $4 \mathrm{~m}$, respectively. From the bottom of the lower subgrade, one layer of geogrid was laid every $1.5 \mathrm{~m}$, with a total length of $6 \mathrm{~m}$, and another layer of geogrid was laid at a distance of $2 \mathrm{~m}$, with a length of $5 \mathrm{~m}$.

The settlement of the subgrade at the horizontal cut to fill subgrade with time is shown in Figure 15, and the settlement of the excavated subgrade, the filling subgrade, and the slope toe were observed, respectively.

It can be seen from Figure 15 that the settlement on one side of the excavated subgrade applied the two kinds of geogrid laying schemes was small, reaching $3.3 \mathrm{~cm}$ on $210 \mathrm{~d}$, and the settlement value applied the two schemes was very close. The difference of settlement value on 210th day was $0.3 \mathrm{~cm}$, which showed that the control effect of different geogrid laying schemes on the settlement of the excavated subgrade was not very different. The differential settlement value on both sides of the subgrade reached $4.1 \mathrm{~cm}$ in 210 days, and the human comfort level was poor. The differential settlement value on both sides of the subgrade filling and excavating side applied the improved scheme was $3.1 \mathrm{~cm}$ in 210 days, and the human comfort level was good. The improved scheme can significantly improve the driving comfort. The original scheme had five layers of geogrids, and the total length was $50 \mathrm{~m}$. A total of 6 layers of geogrids with a length of $41 \mathrm{~m}$ were installed in the improved scheme. The improved scheme had higher utilization rate of the geogrid and better laying scheme.

5.2. The Longitudinal Cut to Fill Subgrade. The original design scheme: two layers of bidirectional geogrid were laid on the top surface of the upper and lower subgrades and the bottom surface of the lower subgrade. The total length of the geogrid was $23 \mathrm{~m}$, of which the length of the digging section was $8 \mathrm{~m}$ and the length of the filling section was $15 \mathrm{~m}$. Five layers of grids were arranged below the subgrade. The grid length was $15 \mathrm{~m}$ and the interval was $1.5 \mathrm{~m}$.

The improvement scheme: two layers of bidirectional geogrid were laid on the top and bottom of the upper and lower subgrades, with a total length of $28 \mathrm{~m}$, including $10 \mathrm{~m}$

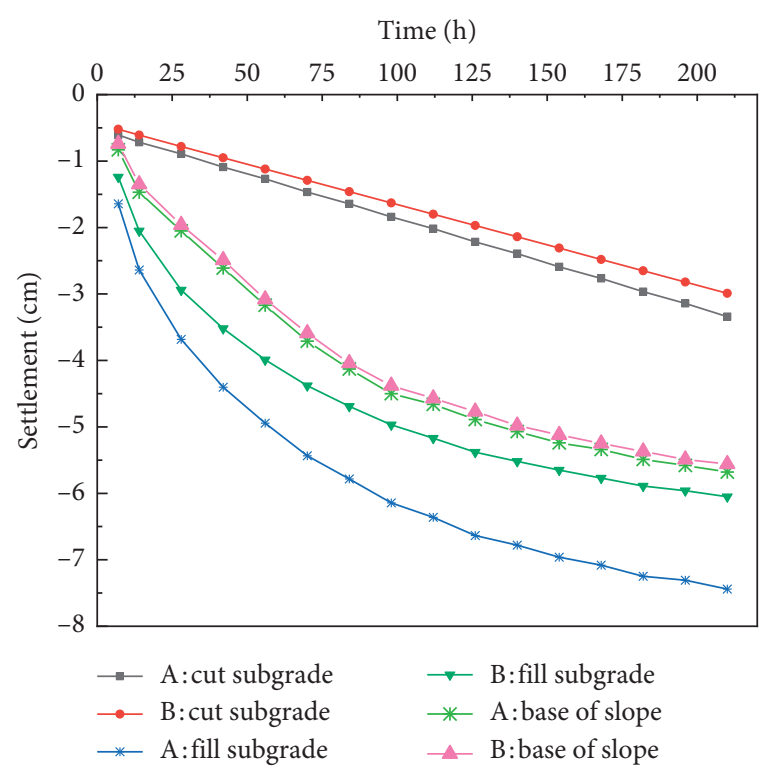

FIgURE 15: Development law of settlement of the horizontal cut to fill subgrade.

excavation section and $18 \mathrm{~m}$ filling section. From the bottom of the lower subgrade, two layers of geogrids were laid every $1 \mathrm{~m}$, with a total length of $16 \mathrm{~m}$, and then two layers of geogrids were laid at a distance of $1.5 \mathrm{~m}$, with a length of $15 \mathrm{~m}$. Two additional geogrids were laid in the depth range of $10-20 \mathrm{~m}$, and the length of the grids was $15 \mathrm{~m}$.

The settlement of the subgrade at the longitudinal cut to fill subgrade with time is shown in Figure 16.

It can be seen from Figure 16 that the improvement scheme makes the transition of the longitudinal cut to fill subgrade deformation more uniform; under the original design scheme, the differential settlement values on both sides of the cut to fill subgrade reached $8.5 \mathrm{~cm}$ in $210 \mathrm{~d}$, and the human body comfort level was poor. Under the improved scheme, the differential settlement value on both sides of the cut to fill subgrade was $6.6 \mathrm{~cm}$ in $210 \mathrm{~d}$, and the human body comfort level is good, so the improved scheme could improve 


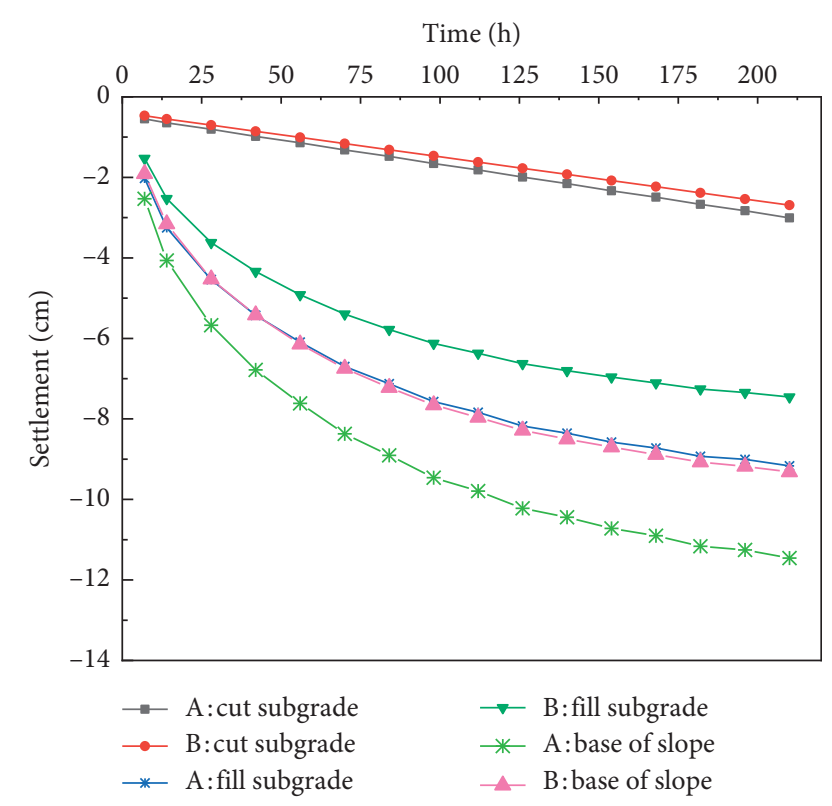

Figure 16: Development law of settlement of the longitudinal cut to fill subgrade.

the driving comfort; the original scheme had 11 layers of geogrids with a total length of $213 \mathrm{~m}$. The improvement scheme had 9 layers of geogrids with a total length of $176 \mathrm{~m}$, indicating that the improved scheme had higher utilization rate of the geogrid than the original laying scheme.

\section{Conclusions}

This paper introduced the driving comfort index innovatively and proposed the subgrade differential settlement control standard based on driving comfort. Based on the finite element analysis, the geogrid layout schemes under different distribution distances of different speeds and differential settlements were established, which provides reference for the laying of geogrid in mountain roads. Some conclusions can be obtained.

(1) Based on the vibration and displacement characteristics of people, vehicles, and roads, the model of man-vehicle-road coupling system was established. The influence of subgrade differential settlement area, subsidence value, and vehicle speed on the maximum vertical acceleration of the human body was analyzed, and the key factors affecting driving comfort in the curve mode of subgrade deformation were determined.

(2) Through multiple regression calculations, the correlation between vertical acceleration of the human body and differential settlement under different driving speeds was obtained, and the driving comfort index was introduced innovatively. Based on this, the subgrade differential settlement control standard based on driving comfort was proposed.

(3) Based on the actual working conditions, the finite element model of the subgrade for cut to fill subgrade was established. The different distribution characteristics of the top surface of the subgrade under different geogrid laying positions, densities, and lengths were calculated and analyzed. It was proposed that the position and length of the geogrid were the main factors affecting the geogrid treatment effect on the subgrade of longitudinal and transverse filling and excavation junction.

(4) Combining the driving comfort difference settlement control standard and the treatment effect of differential settlement of subgrade under different geogrid laying parameters, taking the speed of the vehicle and the distribution distance of uneven settlement sections as an indicator, the layout scheme of geogrid disposal subgrade differential settlement based on driving comfort was established, and the effectiveness of the scheme was verified by experiments.

In conclusion, it was a very effective means to treat the differential settlement of subgrade with geogrid. The research results of this paper provide reference for the geogrid layout scheme in mountain road. If the actual mechanical response of the geogrid can be fully considered, this paper would be more complete. Next, the grid mechanical response and the damage in the construction of the geogrid will be further studied to improve the subgrade construction level and grid utilization.

\section{Data Availability}

The test data used to support the findings of this study have been deposited in the Hindawi (Advances in Materials Science and Engineering) repository. The test data are included within the article and can be made freely available.

\section{Conflicts of Interest}

The authors declare no conflicts of interest.

\section{Acknowledgments}

Thanks to all those who have provided guidance and assistance for this article. This work was supported by the Gansu Province Science and Technology Major Project (1302GKDA009), Gansu Provincial Department of Transportation Science and Technology Project (2016-05), Gansu Luqiao Construction Group Science and Technology Project (2018-BXSG-QT17), and Inner Mongolia Autonomous Region Transportation Science and Technology Project of China (NJ-2018-23).

\section{References}

[1] Y. M. Wang, Q. Z. Li, and S. Q. Gao, "Experimental investigation into effect of differential settlement on working performance of geogrid reinforced embankment," Journal of South China University of Technology, vol. 39, no. 9, pp. 68-74, 2011, in Chinese. 
[2] Y. M. Wang, H. Yi, and Q. Z. Li, "Model tests on working performance of geogrid reinforcement influenced by differential settlement," Advanced Materials Research, vol. 255-260, pp. 3376-3381, 2011.

[3] A. Zofka and M. Maliszewski, "Practical overlay design method for geogrid reinforcement of asphalt layers," Road Materials and Pavement Design, vol. 20, no. 1, pp. S163-S182, 2019.

[4] E. C. Shin, B. M. Das, E. S. Lee, and C. Atalar, "Bearing capacity of strip foundation on geogrid-reinforced sand," Geotechnical \& Geological Engineering, vol. 20, pp. 169-180, 2002.

[5] A. S. A. Al-Hedad and M. N. S. Hadi, "Effect of geogrid reinforcement on the flexural behaviour of concrete pavements," Road Materials and Pavement Design, vol. 20, no. 5, pp. 1005-1025, 2019.

[6] G. W. Hu and Q. M. He, "Experimental study on the reinforcement effect of geogrid in fill embankment," Chinese and Foreign Highways, vol. 38, no. 1, pp. 38-42, 2018, in Chinese.

[7] M. H. Zhao, L. Zhang, X. J. Zou et al., "Research progress of geocell-gravel pile two-way reinforced composite foundation," China Journal of Highways, vol. 22, no. 1, pp. 1-10, 2009, in Chinese.

[8] Y. J. Lu, "Analysis of working mechanism of composite foundation with inclined base soft soil pile net," Railway Construction, vol. 58, no. 3, pp. 54-58, 2018, in Chinese.

[9] X. Y. Wang, B. Peng, X. C. Tang, and L. Fan, "Numerical simulation for uplift bearing capacity and affecting factors of the digging piles in slope ground," Applied Mechanics and Materials, vol. 423-426, pp. 1292-1295, 2013.

[10] A. Petriaev, A. Konon, and V. Solovyov, "Performance of ballast layer reinforced with geosynthetics in terms of heavy axle load operation is," Procedia Engineering, vol. 189, pp. 654-659, 2017.

[11] Y. Q. Zhang, X. C. Wang, C. H. Wang et al., "Numerical simulation and field test at the cut to fill location of subgrade treated with geogrids," Journal of Traffic \& Transportation Engineering, , vol. 8, no. 3, pp. 63-67, 2008, in Chinese.

[12] V. A. Sakleshpur, M. Prezzi, R. Salgado, N. Z. Siddiki, and Y. S. Choi, "Large-scale direct shear testing of geogrid-reinforced aggregate base over weak subgrade," International Journal of Pavement Engineering, vol. 20, no. 6, pp. 649-658, 2019.

[13] W. Wang, J. Wang, J. H. Xue, Z. Xue, and D.-P. Ou, “Analysis of model tests on soft soil subgrade reinforced by geogrid," Rock \& Soil Mechanics, vol. 26, no. 12, pp. 1885-1891, 2005, in Chinese.

[14] X. J. Hao, X. W. Li, Y. C. Guo et al., "Dynamic response analysis of pile-supported reinforced subgrade under oblique incidence of seismic waves," Highway, vol. 63, no. 1, pp. 1-5, 2018, in Chinese.

[15] L. S. Shen, G. Q. Yang, H. T. Cheng et al., "Optimization technology for geogrid-reinforced subgrade widening projects of highways," Chinese Journal of Geotechnical Engineering, vol. 35, no. 4, pp. 789-793, 2013, in Chinese.

[16] J. Y. Geng, X. Jiang, and Y. J. Qiu, "Dynamic simulation of the whole process of highway subgrade widening under the treatment of soft soil foundation," Journal of Chongqing Jiaotong University (Natural Science Edition), vol. 32, no. 6, pp. 1179-1185, 2013, in Chinese.

[17] X. Jiang, Y. Chen, Y. Wu et al., "Numerical simulation of the stability evolution of reinforced retaining wall with reinforced retaining wall," Journal of Southwest Jiaotong University, vol. 53, no. 5, pp. 1000-1008, 2018, in Chinese.
[18] S. H. Mousavi, M. Gabr, and R. Borden, "Optimum location of the geogrid reinforcement in unpaved road," Canadian Geotechnical Journal, vol. 54, no. 7, pp. 1047-1054, 2017.

[19] L. Yadu and R. K. Tripathi, "Effect of the length of geogrid layers in the bearing capacity ratio of geogrid reinforced granular fill-soft subgrade soil system," Procedia-Social and Behavioral Sciences, vol. 104, no. 3, pp. 225-234, 2013.

[20] S. Lerspalungsanti, A. Albers, S. Ott, and T. Düser, "Human ride comfort prediction of drive train using modeling method based on artificial neural networks," International Journal of Automotive Technology, vol. 16, no. 1, pp. 153-166, 2015.

[21] Y. Matsumoto and M. J. Griffin, "Effect of phase on discomfort caused by vertical whole-body vibration and shockExperimental investigation," The Journal of the Acoustical Society of America, vol. 111, no. 3, pp. 1280-1288, 2002.

[22] Mechanical Vibration and Impact-Evaluation of Human Exposure to Whole Body Vibrations Part 1: General Requirements, GB/T.13441.1-2007, China Standard Press, Beijing, China, 2007, in Chinese.

[23] Z. W. Gao, Research on Balanced Settlement Control of Highway Soft Foundation Transition Section Based on Ride Comfort, Ph.D. Thesis, Chang'an University, Xi'an, China, 2012.

[24] G. Y. Liao and X. M. Huang, Abaqus Application of Finite Element Software in Road Engineering, Southeast University Press, Nanjing, China, 2nd edition, 2014. 